\title{
OS LOUVORES MUSICAIS NO RENASCIMENTO ITALIANO: COMENTÁRIOS E TRADUÇÃO DO EXÓRDIO AO "PRUDENTE LEITOR” DO TRATADO IL TRANSILVANO - DIÁLOGO SOBRE A MANEIRA CORRETA DE TOCAR ÓRGÃO E INSTRUMENTOS DE TECLADO - DE GIROLAMO DIRUTA (1593)
}

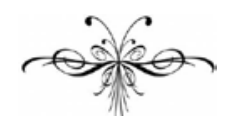

\author{
GiROLAMO DiRUTA
}

DELPHIM REZENDE PORTO

Resumo: A tradução de escritos humanistas de música é uma tarefa complexa. Conhecer com profundidade o assunto tratado, os idiomas relacionados à obra e seu contexto histórico são apenas pontos de partida para o eficiente reconhecimento das tópicas que seus autores visitavam em suas escritas literárias, e consequentemente sua "perfeita" tradução. O pensamento próprio da cortesania e a grande difusão de obras da Antiguidade Clássica visitadas como modelos de forma e topoi nas mais diversas produções renascentistas, sobretudo no século XVI - articulam nos tratados musicais conhecimentos históricos, retóricos e filosóficos, além dos técnicos e próprios do exercício da arte - tendo sempre como fim o deleite, persuasão e instrução dos “prudentes” leitores. Obra referencial da produção musical para teclados - órgão e cravo, principalmente - o Il Transilvano de Girolamo Diruta (1554?-1610?) é exemplo e modelo da tratadística musical que une assuntos particulares da arte à retórica e de seu legado tópico difundido sob a influência humanista. Pretende-se, assim, demonstrar o paratexto e os artifícios de que o autor lança mão na escrita do exórdio do Tratado, e propor sua tradução para a língua vernácula.

Palavras-chave: Tradução retórica. Música. Renascimento. Girolamo Diruta. Tratadística musicais.

\begin{abstract}
The translation of humanistic writings about music is a complex task. A deep knowledge of the subject, of the languages involved, and of the works' historical contexts are just the beginning for one to efficiently recognize the topics that the authors of those works dealt with in their literary writings, and to do "perfect" translations of them. In the Renaissance, the typical thought at the courts associated with the diffusion of the works of Classical Antiquity - seen as formal models and topoi for various productions during the time, especially in the $16^{\text {th }}$ century - articulate a collection of historical, rhetorical and philosophical knowledge - besides musical -, that aimed always at the delight, persuasion and instruction of the “prudent” readers. Girolamo Diruta's (1554?1610?) treatise Il Transilvano is a reference in keyboard studies - organ and harpsichord - and an example and model of musical treatises that incorporate to it subjects such as art and rhetoric. This paper aims at introducing the paratext (the exordium) as well as the devices the author used in its writing, and at offering a translation of the exordium into Brazilian Portuguese.
\end{abstract}

Keywords: Rhetoric translation. Music. Renaissance. Girolamo Diruta. Musical treatises.

Scientia Traductionis, $n .15,2014$ http://dx.doi.org/10.5007/1980-4237.2014n15p391 
$\mathrm{O}$ bra do padre Girolamo Diruta (1554?-1610?), franciscano da ordem dos frades menores, o tratado de música Il Transilvano é um diálogo retórico sobre a maneira correta de tocar órgão e instrumentos de teclado. Publicado em duas partes na Libraria della Pigna por Giacomo Vincenti em 1593 e 1609, respectivamente, é um dos mais importantes tratados para o estudo do repertório e da técnica tecladística quinhentista. A exemplo dos humanistas de seu tempo, o Pe. Diruta expõe eloquentemente as tópicas da música, tal como um orador perfeito que persuade e move sua audiência. Através das doxas e opiniões das auctoritates clássicas que iluminavam aquela sociedade, o autor traz aos olhos os argumentos e assuntos técnicos da arte da música de modo cortês. Para além do registro literário do conhecimento artístico exigido para tal empreendimento, o estatuto cortesão da música naquele tempo determinava aos autores um expediente decoroso e erudito na escrita inartística dos tratados.

O músico humanista, também chamado de valent'huomo por Girolamo Diruta, é um cortesão retórico - facilmente confundido literariamente com o gentilhuomo - que além de dominar tecnicamente o seu instrumento e os conhecimentos estabelecidos na musica prattica também frequenta as autoridades de seu tempo e transita, ao menos em termos discursivos, entre os cultos de seu tempo - pois, tanto artífices da música quanto nobres gentis-homens dispõem do mesmo repertório de argumentos progymnasmáticos.

Os tratados de música escritos até o século XVIII, de maneira geral, assim como outros documentos do período, estão sujeitos às preceptivas e regras da retórica quanto à sua invenção e escrita. Compreendê-los a partir dessa instituição nos permite analisá-los segundo aquela regra sob a qual foram concebidos e livrá-los de interpretações anacrônicas. Diruta obedece à lógica de seu tempo e, de fato, compõe uma obra que discursa artificiosamente tópicas e conteúdos práticos de maneira coerente quanto à forma, destinatário e a ocasião de sua leitura. Tais textos admitem como invenção tudo aquilo que se relaciona à disposição, criação e argumentação a fim de melhor convencer seus leitores músicos e cortesãos, a partir das opiniões de diversas autoridades filosóficas. De fato, aqui, a amplificação retórica, típica do orador, funciona como o exercício da exposição do assunto a partir das opiniões acerca do mesmo e não, necessariamente, da coisa em si. Embora os lugarescomuns desses tratados se relacionem basicamente, por um lado, aos fins da música como ócio cortesão relido a partir da "Política" de Aristóteles, por exemplo, de outro, há uma grande difusão das doutrinas especulativas da música, imitadas de textos gregos e latinos - Pitágoras e Boécio, principalmente.

Com o intuito de oferecer em língua portuguesa um texto que pudesse ser bem compreendido pelo músico contemporâneo e que também fizesse justiça ao seu paratexto e sua história, esforçamo-nos em traduzir não só as palavras e ideias do texto em questão mas, sobretudo, seu espírito e estilo. De fato, a tradução de textos de tal natureza vai muito além da dimensão linguística e inspira uma leitura mais ampla, conforme prescreve, em grifos nossos, naquele mesmo período histórico, Leonardo Bruni (2006, p.55), no contexto da tradução de obras antigas:

Na realidade há muitos que são idôneos para compreender, mas não para explicar. Analogamente, há muitos capazes de julgar corretamente uma pintura mesmo sendo incapazes de pintar, e muitos entendem de música, sendo ineptos para o canto. Traduzir corretamente é uma tarefa importante e difícil. Em primeiro lugar, deve-se ter conhecimento da língua da qual se traslada; não basta um conhecimento superficial e comum; tem que ser profundo e abrangente, adquiri- 
do mediante o ensinamento dos filósofos, oradores, poetas e outros escritores. Ninguém, sem tê-los lido e relido à exaustão, conseguiria compreender a força e o significado das palavras.

Para a tradução do exórdio ao "prudente leitor” do tratado Il Transilvano, procuramos estudar as reflexões sobre esse tema de autores do Renascimento principalmente, assim como fornecer ao pesquisador da música interessado em praticar aquele repertório histórico subsídios para a melhor compreensão daquelas obras musicais em seu contexto genético, possibilitando aos artistas que se dedicam à música renascentista o necessário contato com as preceptivas daquele importante autor. $^{1}$

\section{As tópicas do Exórdio ao Il Transilvano}

Exórdio ou exordium, segundo Aristóteles (2012 [Séc.IV A.C.], p.103), é, em termos retóricos, o início de um discurso (oral ou escrito) e tem por finalidade essencial dispor o ouvinte para os assuntos que serão expostos. Além de trazer os elementos fundamentais do tema, essa introdução deve captar a benevolência do leitor e dispô-lo convenientemente à exposição do orador. "Corresponde ao prólogo na poesia e na música de aulo ao prelúdio [..] e são início e preparação do caminho para o que segue”.

No exórdio do Il Transilvano, situado no primeiro volume, publicado em 1593, Diruta compõe um refinado louvor do órgão e dispõe tal leitor ao tratado que segue. Por 'prudente', Raphael Bluteau (1638-1734), na obra "Vocabulario Portuguez e Latino” (publicada em Coimbra em 1712), entende aquela virtude intelectual que ensina ao homem o reto modo de obrar e o que é moralmente bom ou mau para abraçá-lo ou fugi-lo. Primeira das virtudes cardeais, a prudência é descrita, alegoricamente, como uma amoreira, a mais sábia das árvores - porque ao dar suas flores mais tarde que as demais, protege-as da geada -, encimada por Janus com duas cabeças, uma com os olhos para o passado e, a outra, para o futuro. Essa invenção nos parece coerente para o argumento do órgão, uma vez que é um instrumento muito antigo - descrito por Vitruvio (2007, p.507) no livro X, capítulo oitavo, como uma engenhosa máquina organa, hidráulica, com teclas e, que serve às artes musicais e, ao mesmo tempo, encomiado aqui como um instrumento excelente, estável e de valor para o futuro.

Iniciado o argumento, Diruta o desenvolve a partir da figura retórica da antonomásia, que opera através da substituição de um nome próprio e real, por um outro, com vistas ao louvor, por excelência, ou ao vitupério. É, por exemplo, que se diz, por antonomásia, Salvador no lugar de 'Jesus Cristo', Aleijadinho em vez de

\footnotetext{
${ }^{1}$ Quanto ao artifício formal da tradução, tomamos o texto diretamente da publicação primeira e o transcrevemos mantendo as diferenças que as publicações da época consideram para a ortografia das palavras. Na mesma página, temos de um lado a transcrição fiel do texto em italiano antigo e, do outro, a sua versão em língua portuguesa. O leitor, então, pode comodamente comparar ambos os textos e fazer suas considerações sobre o mesmo auxiliado por uma introdução precedente. Para a tradução dos conceitos principais consideramos primeiramente a sua correspondência nos escritos portugueses contemporâneos ao Transilvano e a sua ressonância atual. A esse propósito, é importante destacar que aqueles antigos mestres também estavam cunhando seu léxico próprio vulgar, e nem sempre os termos adotados à época, sobreviveram em ambas as línguas.
} 
'Antônio Francisco Lisboa', ou se dá ainda, a um poeta - não-nobre - o título de Excelência: "Todos estes”, escreve Diruta, "por serem excelentíssimos em seu saber, têm por nome a própria Excelência”. Considerando o seu leitor um gentilhomem culto e cristão, o autor, ao elogiar, transita artificiosamente por diversas auctoritates filosóficas e cristãs.

Para esse fim, Diruta, então, argutamente aproveita a múltipla gama de significados que regulam a palavra ‘órgão’ nas endoxa - opiniões retóricas consideradas como verdadeiras por vários sábios sobre qualquer assunto - e compõe a sua imitação, seguindo as preceptivas retóricas da verossimilhança, sobre a qual reflete Hansen (2006, p. 87):

As opiniões tidas por verdadeiras fornecem causas e explicações que tornam o discurso verossímil ou semelhante ao verdadeiro da opinião. A verossimilhança é uma relação de semelhança entre discursos e, na ekphrasis, decorre da relação da imagem fictícia da pintura que é descrita com discursos do costume antigo que fornecem causas e explicações do que é narrado sobre ela, tornando-o semelhante àquilo que se considera habitual e natural. A ekphrasis é falsa fictio, pois narra o que não é; sua audiência sabe disso e a ouve bem justamente porque a ouve como artifício, cujos preceitos são críveis pois aptos para narrar o incrível. Como exercício de eloquência, a ekphrasis é uma pragmática: evidencia justamente a habilidade do orador que espanta a audiência com a narração da falsa fictio, tornando o efeito provável porque sua imaginação é alimentada pelos topoi da memória partilhada.

No livro IX, capítulo quarto, de suas Instituições Oratórias, Quintiliano atribui genericamente o nome organa a todo tipo de instrumento musical. Diruta emula essa tópica e, ainda por antonomásia, declara que o órgão é o instrumento por Excelência: "[...] que recolhe em si todos os outros instrumentos, a virtude de todos os outros [...] e é Rei dos instrumentos, com razão colocado nas Santas Igrejas de Deus”.

É obra do $76^{\circ}$ papa católico Vitaliano I a introdução no culto cristão do órgão como instrumento admitido às liturgias, que antes, eram somente cantadas - tal como ainda é hoje nas igrejas cristãs orientais. Essa dignidade, dada exclusivamente a esse instrumento musical, é em vários momentos citada por nosso autor que, partindo da consideração de Quintiliano, une-a ao uso cristão para um louvor que ao mesmo tempo considera o órgão como a reunião de todos os instrumentos musicais e também como o único instrumento que serve somente, a rigor, ao culto do seu Deus: “como rezado no Salmo (150): Laudate Dominum in cordis, \& organo". Nesse trecho é curiosa a inversão da oração que Diruta utiliza (p.79), ao invés da esperada e natural - [...] que se usa nas Igrejas para acompanhar os coros sacros [...] (destaques nossos):

[...] che s'usa nelle Chiese accompagnato da $\boldsymbol{i}$ sacri chori con le voci de cantori, perche nel Salmo $[\ldots]$
[...] que se usa nas Igrejas acompanhado pelos coros sacros com vozes de cantores - como rezado no Salmo (150)[...]

Embora esse argumento seja fundamental na composição do exórdio, para oportunamente introduzir a figura do sonatore - instrumentista que, para alcançar o fim, que é a música, vale-se de um meio, primeiro significado de instrumento - o autor engenhosamente o confuta justapondo ao texto as tópicas, a partir daí, da música prática. 
Giovanni M. Artusi, na Arte do Contraponto (1585, fl.3), em consonância com o conceito de 'músico perfeito' de G. Zarlino (1558), afirma que o prático da arte da música toma do instrumento que utiliza, o seu nome - do órgão, organista, da voz, cantor, da penna, compositor. O nome 'músico’ poderia somente ser atribuído ao prático que também fosse teórico, especulativo, normalmente acrescido, nesse período, do epíteto 'perfeito'. Afirmando, então, que o órgão não é simplesmente aquele instrumento que serve à igreja e ao culto religioso, o autor salienta que esse é também um instrumento como outro qualquer, meio para o instrumentista exercitar a sua virtude de cantar e tocar:

Nome peraventura non inteso da molti che se credono che Organo non voglia dire altro che quell'istrumento musicale che s'usa nelle Chiese [...] ma veramente si come il Lauto, la Cithara; la Lira, l'Arpicordo, e'l Clavocimbalo, tutti per se stessi si chiamano istrumenti; perche il sonatore gl'usa per mostrare la propria Virtù sua del Cantare, \& del Sonare;
Incompreendido por muitos, o nome 'órgão' não significa somente aquele instrumento musical que se usa nas Igrejas [...] Entretanto, o órgão, é verdadeiramente, como um alaúde, uma cítara, uma lira, uma espineta ou um cravo - que são chamados por si mesmos 'instrumentos' (meios) e utilizados pelo instrumentista para demonstrar sua própria virtude de cantar e tocar.

De todas as amplificações e emulações retóricas que Diruta expõe nesse exórdio, certamente a mais elaborada e aguda é a que realiza - embora não declaradamente - a partir do Da Alma de Aristóteles. Ainda que não fosse costume, para essa operação, evidenciar ou citar a "fonte" do artifício, certamente, àquele público, tais tópicas eram bem conhecidas, pois a elaboração de lugares comuns dentro do discurso, mais que um procedimento engenhoso, era grande motivo de prazer intelectual para a audiência.

Desse modo, faz-se necessário ao pesquisador moderno que deseja compreender escritos dessa estirpe instruir-se a partir das fontes que os autores de tais escritos reportavam como topoi, para perceber o texto além do texto. No quadro abaixo, procuramos evidenciar a semelhança de alguns dos argumentos elaborados por Diruta, comparando-os com a fonte aristotélica.

\section{Il Transilvano - original \\ con la medesima ragione la mano nel corpo humano è detta Organo de gl'Organi, cioè istrumento che per operare, si serve di tutti gl'istrumenti, che ap- partengono all'operatione del l'artificio.}

$\&$ tanto maggiormente è de gli altri più Eccellente \& più nobile, quanto meglio rappresenta la voce humana, operandosi in esso il fiato, \&

\begin{tabular}{|} 
O Transilvano - tradução \\
[...] Pelo mesmo \\
motivo, a mão no corpo \\
gão dos órgãos', ou seja, \\
instrumento que para ope- \\
rar, se serve de todos os \\
instrumentos [meios] per- \\
tinentes à realização do ar- \\
tifício. \\
[...] e é mais exce- \\
lente e mais nobre que os \\
demais, por melhor repre- \\
sentar a voz humana, va- \\
lendo-se para isso, do so- \\
pro e da mão.
\end{tabular}

\section{Aristóteles - De anima} (2001)

432a1. Também a alma é, ela mesma, análoga à mão: a mão é o instrumento de todos os outros instrumentos.

420b5. (...) podemos dizer que a voz, ela mesma, é um som emitido por um ser animado. Com efeito, nenhum dos seres inanimados pode possuir 
la mano.

Et le canne di qual materia elle si siano, rappresentano le fauci humane, per doue passa lo Spirito à formare il suono, \& la voce

che quasi si puo securamente dire, che l'Organo sia vno Artificioso Animale, che parli, suoni, \& canti con le mani, \& con l'arte dell'huomo, \& che per tale cagione sia nel Tempio di Dio
Os tubos, independentemente do material de que são feitos, são como a garganta do Homem por onde passa o espírito que forma o som e a voz.

Se pode quase seguramente dizer que o órgão é um animal artificioso que fala, soa e canta com as mãos e com a arte do homem, e por tal razão está no Templo de Deus. voz, sendo unicamente por analogia que podemos atribuir a este uma voz, como acontece, aliás, com a flauta, a lira e outros objetos inanimados que possam incluir registro, melodia e linguagem, parecendo mesmo que a própria voz pode, ela mesma, incluir estes elementos. (...) A voz é, portanto, o som emitido por um animal (...).

A natureza, na verdade, utiliza o ar inspirado para dois fins, assim empregando a língua e o gosto da linguagem, sendo este gosto uma função necessária.

420b20 A voz é a perfeição do ser animado.

Quadro 1 - Comparação entre a matéria desenvolvida por Diruta e aquela imitada.

O artifício supracitado caracterizaria o órgão a partir dos órgãos e as faculdades da Alma segundo a doxa aristotélica. Basicamente situadas no livro II do ' $\mathrm{Fi}$ lósofo', as matérias emuladas por Diruta buscam alegoricamente relacionar 'corpo', 'órgão', 'alma' e 'organista'. Dois meios para essa justaposição merecem destaque: a mão - "órgão dos órgãos” do instrumentista que toca - e o ar - que vem dos foles e enche o órgão com o espírito:

420b30. Não obstante, nem todo o som emitido por um animal pode ser conside-
rado voz (podemos, com efeito, produzir um ruído apenas movendo a língua).
Por outro lado, é necessário que aquele ser, responsável pela produção do cho-
que, seja um ser animado e que, além disso, possua ainda algum poder de repre-
sentação. (ARISTÓTELES, 2001, p. 75)

Nas palavras de Diruta o órgão é um “animal artificioso”, verdadeiramente "um corpo governado pela alma”, que é o homem. O autor, então, descreve as partes do órgão em relação aos órgãos do corpo humano amplificando a tópica aristotélica. Segundo o artifício, os foles correspondem ao pulmão, os tubos, à garganta, as teclas, aos dentes e, por língua, o órgão “possui” as mãos do organista que, através da sua boa arte pode fazê-lo suavemente tocar e, "de doce maneira, quase falar". A ekphrasis, que o autor traz aos olhos do leitor, e que serve de primeira justificativa para a escrita dessa obra, é a de um homem bem feito em todas as suas partes que, embora tenha uma aparência bem proporcionada, não possui língua capaz de expor aquilo que possui dentro de si enquanto intelecto, e, ao falar, estraga e desacredita seu engenho. 
Do ponto de vista da cortesania, é sumário expressar-se coerentemente ao que se é enquanto nobre. A prescrição do modo de agir do gentil-homem é desenvolvida em muitos tratados italianos do período em questão, como o Galateo overo de' costumi (1558) de Giovanni Della Casa (1503-56). O decoro, enquanto coerência de fins e meios, no caso, do organista com o órgão - um dos assuntos da primeira parte do nosso tratado - pode ser lida à luz das mesmas prerrogativas que aquela sociedade considerava para a vida virtuosa, "Armonia è bellezza" nas palavras de tantos autores do cinquecento. Para um fim nobre, um justo meio. Expressar prudência, virtude e outras qualidades nobres, através dos atos, percorre a vida do cortesão desde o sentar-se à mesa, passando pelo exercício da eloquência, até a escolha do instrumento que deve ou não tocar. A confusão entre um fim alto com um meio baixo pode ser razão de vitupério daquele que o faz, ou por vaidade - no Galateo, por exemplo, se considera vaidade ser excessivamente cerimonioso em ocasiões baixas - ou por ser procedimento cômico, portanto, relativo ao bufão e não ao nobre.

O órgão por ser nobre instrumento e de ocasião sacra requer da parte do organista, conforme prescrito por Diruta, um cuidado especial. Enquanto "língua" do "animal artificioso", o instrumentista ou gentil-homem que toca, deve observar as mesmas disposições do decoro cortês na execução musical.

Por último argumento do exórdio, Diruta utiliza a tópica platônica da música como sendo capaz de formar, alterar e mover o ânimo do ouvinte, penetrando no íntimo daquele que a escuta. Tal força, no caso do órgão, tem um fim nobre e justo: o de atrair os fiéis para o culto divino. Essa capacidade justifica plenamente, para o autor, a razão de esse instrumento possuir um lugar especial no templo sagrado. Como procedimento típico da captatio benevolentiae, Diruta justifica que, embora tão magnífico e tocado por tão valentes organistas, para o órgão, não havia antes da sua obra, Regra para sua perfeita compreensão, e a escrevia, assim, por diversos clamores, entre eles o do famoso organista Claudio Merulo - seu preceptor nesta arte.

\section{Tradução do exórdio}

\author{
L'Autore dell'Opera \\ al Prvdente Lettore
}

Tutte l'arti, \& tutte le scienze, che dall'intelletto humano si comprendono, per dispositione della somma Prouidenza di Dio, si riducono ad vn principale intelligente, \& Maestro d'esse, che per Eccellenza è da tutti inteso, \& honorato: cosi nella Filosofia, se si dice il Filosofo è subito inteso Aristotele. Nella Medicina quando si nomina il Medico, si comprende Hipocrate. Nella Poetica tra latini, col no-
Do Autor da Obra ao Prudente Leitor 
me di Poeta, si honora Vergilio, \& tra volgari il Petrarca. Nelle sacre lettere quando si fa mentione del Profeta, intendiamo Davide, come nel dire l'Apostolo s'intende sempre S. Paolo. Poiche tutti questi per essere Eccellentissimi nel loro sapere, ritengono il nome della propria Eccellenza quel che avvenne anticamente nella facoltà della musica, dandosi il titolo dell'Eccellenza ad Orfeo, \& ad Anfione. Et chiaramente veggiamo, che si dà hoggi a gli istrumenti musicali, chiamandosi per Eccellenza, Organo quello che racconglie in se tutti gl'altri, cioè la Virtù di tutti gl'altri istrumenti, con li quali il valore della musica, ne le vo$\mathrm{ci}$, \& ne' suoni soavemente si scopre; onde l'Organo, cosi chiamato è Rè de gl'istrumenti ragionevolmente tenuto nelle Chiese sacre di Dio, per rendere lode \& honore à Sua Maestà: con la medesima ragione la mano nel corpo humano è detta Organo de gl'Organi, cioè istrumento che per operare, si serve di tutti gl'istrumenti, che appartengono all'operatione del l'artificio. Nome peraventura non inteso da molti che se credono che Organo non voglia dire altro che quell'istrumento musicale che s'usa nelle Chiese accompagnato da i sacri chori con le voci de cantori, perche nel Salmo Laudate Dominum in cordis, \& Organo; ma veramente si come il Lauto, la Cithara; la Lira, l'Arpicordo, e'l Clavocimbalo, tutti per se stessi si chiamano istrumenti; perche il sonatore gl'usa per mostrare la propria Virtù sua del Cantare, \& del Sonare; cosi l'Organo, che per Eccellenza è cosi chiamato, raccoglie in se stesso tutti gli istrumenti musicali, \& tanto maggiormente è de gli altri più Eccellente \& più nobile, quanto meglio rappresenta la voce humana, operandosi in esso il fiato, \& la mano. Et le canne di qual materia elle si siano, rappresentano le fauci humane, per doue passa lo Spirito à formare il suo-
'Poeta' se honra Virgílio, e entre os vulgares, Petrarca. Nas Sagradas Escrituras, quando se diz 'Profeta' entendemos Davi e quando se enuncia 'Apóstolo' imaginamos sempre São Paulo. Todos esses, por serem excelentíssimos em seu saber, têm a própria Excelência por nome. Na faculdade da Música, antigamente, se deu a Orfeu e a Anfião o título da Excelência. Hoje claramente vemos o que se sucede aos instrumentos musicais, chamando-se por Excelência, o órgão: instrumento que encerra em si todos os outros, a virtude de todos os outros instrumentos - com os quais, suavemente, se descobre o valor da música, das vozes e dos sons. $\mathrm{O}$ assim chamado 'Órgão' é o Rei dos instrumentos, com razão colocado nas Santas Igrejas de Deus, para render louvor e honra à Sua Majestade. Pelo mesmo motivo, a mão no corpo humano é chamada 'Órgão dos órgãos', ou seja, instrumento que para operar, se serve de todos os instrumentos [meios] pertinentes à realização do artifício.

Incompreendido por muitos, o nome 'órgão' não significa somente aquele instrumento musical que se usa nas Igrejas acompanhado pelos coros sacros com vozes de cantores - como rezado no Salmo (150): Laudate Dominum in cordis, \& Organo. Entretanto, o órgão é verdadeiramente como um alaúde, uma cítara, uma lira, uma espineta ou um cravo - que são chamados por si mesmos 'instrumentos' [meios] e utilizados pelo instrumentista para demonstrar sua própria virtude de cantar e tocar.

Desse modo, o órgão - que por excelência é assim chamado - contém em si todos os instrumentos musicais, e é mais excelente e mais nobre que os demais, por melhor representar a voz humana, valendo-se para isso, do sopro e da mão. Os tubos, independentemente do material de que são feitos, são como a garganta do Homem por onde passa o 
no, \& la voce, che quasi si puo securamente dire, che l'Organo sia vno Artificioso Animale, che parli, suoni, \& canti con le mani, \& con l'arte dell'huomo, \& che per tale cagione sia nel Tempio di Dio sì bene fabricato, con diversi ornamenti, \& solo operato ne' sacri offitij, per lodare con le voci, \& con i suoni l'opere grandi \& marauigliose di Sua Maestà \& tra tutti $i$ principali istrumenti, che col nome d'Organo sono celebrati, bellissimo è quello della Città di Trento, marauiglioso quella nel Duomo d'Ogobbio, \& degno d'esser veduto \& sentito quello della Chiesa Catedral di Cagli, ne quali tutti si raccolgano gli altri istrumenti con suavissimo concento, \& con dolcissima consonanza. Quelche hauendo io per proua veduto, \& con diligenza compreso, mi sono non poco marauigliato che tra tanti nobilissimi \& Eccellentissimi Organisti, che fino à questa hora hanno sonatosi egregio istrumento, non habbino pienamente posto in luce l'Eccellenza d'esso, e'l modo di ben trattarlo. Però con buona pace di tutti, \& col mantenimento delle loro lodi, ad Honore \& Gloria di Dio, \& à satisfattione delle christiane orecchie, per intelligenza de gli ellevati spiriti, che di sì honorata facoltà si dilettano; ho deliberato con l'aiuto di sua Maestà dare al mondo queste mie volontarie fatiche intorno all'uso di questro illustre istrumento, accioche sì come egli è capo, \& principale di tutti, cosi in buon modo apparisca, \& chiaramente s'intenda, qual sia il vero vso di maneggiarlo, \& quale la dolcezza, \& soavità che rendano in esso insieme bene vniti tutti gli altri instrumenti, per rappresentare in Terra il soavissimo concento de Beati Spiriti in Cielo, in lodare Iddio Benedetto, quelche nell'Organo di San Pietro di Perugia si mostra con vn bel verso dicendo. Haec si contingunt Terris, quae gaudia Caelo? Come si dicesse, Se in Terra si espírito que forma o som e a voz. Se pode quase seguramente dizer que o órgão é um animal artificioso que fala, soa e canta com as mãos e com a arte do homem, e por tal razão está no Templo de Deus. Tão bem fabricado e com diferentes ornamentos, é operado apenas nos ofícios religiosos, para louvar com as vozes e com os sons as grandes e maravilhosas obras de Sua Majestade. Dentre todos os principais instrumentos que com nome de 'órgão' são celebrados, belíssimo é aquele da cidade de Trento, maravilhoso aquele no Domo de Gobbio; e, digno de ser visto e ouvido, aquele da Igreja Catedral de Cagli. Todos eles, com suavíssima harmonia e doce consonância, recolhem completamente em si os outros instrumentos. Tendo visto como prova e isso compreendido diligentemente, fiquei bastante surpreso de constatar que entre tão nobres e excelentíssimos organistas que tocaram até hoje esse extraordinário instrumento, nenhum tenha plenamente evidenciado sua excelência e a correta maneira de operá-lo. Por essa razão, para a paz de todos, e mantendo os louvores daqueles organistas, para honra e Glória de Deus, satisfação dos ouvidos cristãos e inteligência dos espíritos elevados que com tão honrada faculdade se deleitam, deliberei, com a ajuda de sua Majestade, escrever esta obra acerca do uso desse ilustre instrumento, que é superior e principal dentre todos. Assim o faço para que de bom modo apareça e claramente se entenda a sua verdadeira função e manejo e a doçura e suavidade com que reúne todos os outros instrumentos, para representar na Terra o suavíssimo concerto dos beatos espíritos do céu, louvando o Deus bendito, tal como está escrito no órgão de São Pedro de Perugia: Haec si contingunt Terris, quae gaudia Caelo? [Se isto acontece na terra, que gozos no céu?] Como se dissesse: se na Terra [já] se 
gode di tale soaue armonia, con tanto artificio procurata all'orecchie humane; qual godimento, \& gioia debbe essere de'chori Angelici \& de Beati Spiriti in Cielo? È veramente questo merauiglioso istrumento che Organo è per Eccellenza chiamato, come corpo humano governato dall'Anima; poiche come s'è detto, il primo aspetto d'esso, grandemente diletta l'occhio, e'l suono che arriua all'orecchie come parole che significano gl'affetti del cuore, rappresenta l'interna dispositione de lo spirito, che lo gouerna, havendo i mantici corrispondenti al polmone, le canne alla gola, i tasti a' denti, e'l Sonato$r e$ in vece di lingua, che con leggiadri mouimenti della mano lo fà soauemente sonare, \& quasi con dolci maniere parlare. Di qui è, che ogn'uno dourebbe, con ogni suo potere sforzarsi di procedere per li mezzi più perfetti; percioche facendo altrimenti, si potrebbe assimigliare la grandezza d'un tale istrumento, ad vn huomo ben proportionato, in qualunque parte della persona sua, \& che dipoi, habbia vna intricata, \& barbutiente lingua, che in tutto lo disaconti, \& guasti. Mà si come la vaghezza delle figure ben colorite, trahe à se l'occhio de' risguardanti: cosi la soauità de' concenti ben proportionati, arrivando all'orecchie de gli ascoltanti, penetra ne' secreti pensieri, \& nelle celate passioni di quelle. la onde debitamente è posto come in proprio luogo nel Tempio di Dio, accioche con esso s'inuitino, \& quasi si sforzino i deuoti \& fedeli spiriti ad vdire le lodi, \& gli honori, che con gli suoni \& con le voci, bene accompagnate si danno all'altissima Maestà di Dio, il che ragioneuolmente m'ha mosso à darne alcune Regole, \& mostrare alcuni modi à mio giuditio, necessarij per ben conoscere, \& essercitare la Virtù di tale istrumento, cosi richiesto da molti che sentendomi di ciò discorrere m'hanno con molto feruore pregato, regozija com tal suave harmonia, buscada com tanto artifício pelos ouvidos humanos, qual gozo e alegria devem ser os coros angélicos e de Beatos Espíritos no Céu? É verdadeiramente esse maravilhoso instrumento - por excelência chamado de ‘órgão' - como um corpo humano governado pela alma, pois, como foi dito, o seu primeiro aspecto deleita grandemente os olhos, e o som, que chega aos ouvidos como palavras repletas de afetos do coração, representa a disposição interna do espírito que o governa. Seus foles correspondem a um pulmão, os tubos à garganta, as teclas aos dentes, e por língua, tem as mãos do organista, que através de elegantes movimentos, o faz suavemente tocar e, de doce maneira, quase falar. Por essa razão, cada um deveria, com todas as suas forças, se esforçar em proceder senão pelos meios mais perfeitos, pois, fazendo de outra forma, assemelharia a grandeza de tal instrumento a um homem bem proporcionado em todas as suas partes, mas que, no entanto, possui uma fala intrincada e balbuciante, que em tudo o desacredita e estraga.

Tal como a beleza das figuras bem coloridas atrai os olhos dos observadores, a suavidade dos sons bem proporcionados, chegando aos ouvidos da audiência, penetra em seus pensamentos secretos e nas suas paixões mais veladas. Por isso foi devidamente colocado, como em lugar próprio, no Templo de Deus, para atrair e convidar os devotos e fiéis espíritos a ouvir os louvores e as honras que, com sons e vozes bem acompanhadas, se oferecem à altíssima majestade de Deus. Movido por esse espírito, resolvi escrever algumas regras e mostrar alguns modos, necessários, a meu ver, para bem conhecer e exercitar a virtude desse instrumento, tal como me fora requerido por muitos que, ouvindo-me disso discorrer, pediram-me com fervor que pu- 
non che dolcemente essortato à publicare questi miei pensieri al mondo, per comune beneficio di tutti quelli che di tal facoltà musicale si dilettano, \& di ben conseguirla desiderano. II che faccio io tanto piu volontieri, quanto piu mi sento infiammato dal Eccellentissimo Signore Claudio Merulo da Correggio, come per vna sua Epistola nel primo libro suo de Canzoni alla Francese intauolato, si mostra, quanto questa Regola sia necessaria per bene intendere il vero modo di Sonare. Però prego quanto più posso, quelli à chi piacerà di leggere queste mie Regole, che non vogliano incolparmi di troppa arroganza, ò temerità, se io non hauerò pienamente satisfatto à quanto à si nobile impresa si richiede considerando che niuna cosa di qual si sia arte, ò scienza, fù in vn medesimo tempo perfettamente cominciata, \& compita; ma che per gradi, \& spatij di tempo, \& di studio, s'arriua alla perfettione, come spero io che debba auenire, à questa mia nuoua fatica, che da chiari intelleti ben conosciuta, sarà opportunemente honorata \& gradita. blicasse estes meus pensamentos ao mundo, para comum benefício de todos aqueles que se deleitam de tal faculdade musical e, que bem consegui-la desejam.

E o faço ainda com mais gosto e inflamado porque o Exmo. Sr. Claudio Merulo de Correggio através do prefácio do seu primeiro livro de Canzoni alla Francese entabuladas para teclado declara o quanto é necessária essa minha Regra para bem entender a verdadeira maneira de tocar.

Peço, porém, àqueles a quem for agradável ler estas minhas regras, que não me considerem arrogante ou ousado se não conseguir satisfazer plenamente tudo o que esta tão nobre empresa requer. Considerem que nenhuma coisa foi, tanto em arte ou ciência, perfeitamente iniciada e concluída senão gradualmente, através de tempo e estudo: é assim que se chega à perfeição. O mesmo espero que suceda a esta obra: que por doutos engenhos seja reconhecida, e oportunamente, bem acolhida e honrada.

Tradução de:

Delphim Rezende Porto delphim@usp.br Doutorando em Música, Universidade de São Paulo

Fonte: DIRUTA, Girolamo. Il transilvano dialogo sopra il vero modo di sonar organi, et istromenti da pena Fac-símile. Veneza, 1593 e 1609. Bologna: Forni Editore, 1960. 


\section{Referências bibliográficas}

Aristóteles. De Anima. Tradução de Maria Cecília Gomes dos Reis. São Paulo: Ed. 34, 2006.

. Política. Tradução de Nestor Chaves. Bauru: Edipro, 2009.

. Retórica. Tradução de Paulo Farmhouse Alberto, Manuel Alexandre Junior e Abel Do Nascimento Pena. Lisboa: Martins Fontes, 2012.

Artusi, Giovanni Maria. L'arte del Contraponto - facsímile - Veneza, 1586. Bologna: Forni Editore, 1980.

Bluteau, Raphael. Vocabulario Portuguez \& Latino. Coimbra: Colegio das Artes da Companhia de Jesu, 1712.

Bruni, Leonardo. Da Tradução Correta. In: Furlan, Mauri (org.). Clássicos da Teoria da tradução. Volume 4. Florianópolis: UFSC/NUPLITT, 2006.

Della CasA, Giovanni. Galateo overo de' costumi - Veneza: Nicolo Bevilacqua, 1558.

DIRUTA, Girolamo. Il transilvano dialogo sopra il vero modo di sonar organi, et istromenti da pena - Fac-símile -Veneza, 1593 e 1609. Bologna: Forni Editore, 1960.

HAnsen, João Adolfo. Alegoria - Construção e interpretação da metáfora. São Paulo: Hedra, 2006.

Quintiliano, Marco Fabio. Insititutio Oratoria. London: Harvard University Press, 1985.

Vitruvio, Pollio. Tratado de arquitetura. São Paulo: Martins Fontes, 2007. 